\title{
A RESEARCH ON COMPULSORY ORGANIZATIONAL CITIZENSHIP BEHAVIOR, PSYCHOLOGICAL CAPITAL AND ORGANIZATIONAL CYNICISM IN TERMS OF DEMOGRAPHIC FACTORS
}

\author{
DOI: 10.17261/Pressacademia.2021.1445 \\ JBEF- V.10-ISS.3-2021(2)-p.115-126
}

\section{Ferit Olcer $^{1}$, Cengiz Coban ${ }^{2}$}

${ }^{1}$ Hatay Mustafa Kemal University, Faculty of Economics and Administrative Sciences, Hatay, Turkey. folcer@hotmail.com, ORCID: 0000-0001-8826-1923

${ }^{2}$ Hatay Mustafa Kemal University, Hatay, Turkey. cengizcoban@outlook.com, ORCID:0000-0023-0084-1224

Date Received: July 6, 2021

Date Accepted: September 18, 2021

To cite this document

Olcer, F., Coban, C. (2021). A research on compulsory organizational citizenship behavior, psychological capital and organizational cynicisim in terms of demographic factors. Journal Business, Economics and Finance (JBEF), 10(3), 115-126.

Permemant link to this document: http://doi.org/10.17261/Pressacademia.2021.1445

Copyright: Published by PressAcademia and limited licenced re-use rights only.

\section{ABSTRACT}

Purpose- The aim of this research is to reveal whether the COCB, PC and OC levels of the employees, which are the important arguments of the managers for the multifaceted organizational success, differ in terms of demographic factors.

Methodology- For the research application, a staple food producer operating in Gaziantep province and included in the ISO 500 list was selected. The reasons for choosing such a business for research are various, e.g. its proximity to the Middle Eastern countries in terms of geographic location. Therefore, the export potential of Gaziantep is good because of its location to reachout imported raw material and being near by the ports of Iskenderun and Mersin. In addition, the relatively low number of researches conducted in the production sector is another reason for choosing such a business. 310 employees of the enterprise, which has a total of 1200 employees and operates in 5 main groups, were surveyed, and 305 of them were identified as valid, thus the data set was obtained. The research was carried out with a questionnaire application, and demographic variables are present at the beginning of the 33-question questionnaire form. The research model and hypotheses were tested by the SPSS-22 program.

Findings- Research results indicate that while the marital status and education level on $\mathrm{OOCB}$ and $O C$, gender, age and institutional working time, age do not create any differentiation. On PC only educational level creates a differentiation among demographic factors, while age, gender, marital status and institutional working time do not reveal a differentiation.

Conclusion - In the literature, СОCB has not been adequately studied in terms of demographic factors, and the effect of demographic factors on COCB, $P C$ and $O C$ has never been investigated collectively. For this reason, this study differentiates it from other research and fills a gap in the literature from this point of view, making a significant contribution. A research on whether Compulsory Organizational Citizenship Behavior $(\mathrm{COCB})$, Psychological Capital (PC) and Organizational Cynicism (OC) differ in terms of demographic factors is included through the employees of a selected company. In the literature, the effects of demographic factors on $\mathrm{COCB}, \mathrm{PC}$ and $\mathrm{OC}$ were discussed one by one and different results were found. Examining the impact of multiple demographic factors on $C O C B$ and collectively examining their impact on $C O C B, P C$ and $O C$. Hiring more educated staff for higher PC level and lower COCB and OC level. Preference for single personnel in terms of marital status factor for higher PC level and lower COCB and OC level.

Keywords: Compulsory organizational citizenship behavior, psychological capital, organaizational cynicism, demographic factors JEL Codes: L10, L12, L13

\section{INTRODUCTION}

Considering that employees, namely human resources, are the most important production factors for strategic management, sustainable growth, sustainable competition and profitability in enterprises, businesses that realize the synergetic power added by human resources to the system have to use organizational behavior concepts to use it. Examining these concepts is one of the most important arguments of managers. Although the relatively high destructive effect of negative organizational behavior 
concepts on organizations is mentioned, using positive organizational behavior variables as a solution is seen as a way. At this point, the concept of COCB is not rather than being a new negative organizational behavior variable on its own, the concept of $O C B$ is considered to be a concept that is perceived as a result of some pressure, but is actually a destructive concept for the organization. The concept of PC, on the other hand, emerged with the idea of competitive advantage, and it is a concept that further diversifies traditional capital and is evaluated in a specific way as positive psychological capital. Consisting of the dimensions of hope, psychological resilience, self-efficacy and optimism, PC is becoming one of the most important arguments of businesses and organizations in gaining competitive advantage today. Finally, the concept of OC is one of the important negative organizational behavior types that can affect the profitability of businesses, especially in today's competitive working environment.

The aim of this study is to examine whether the levels of COCB, PC and OC differ in terms of demographic factors as a result of considering the synergistic power and vital role that employees add to the system in terms of enterprises. Among these concepts, COCB is a new concept and has not been sufficiently studied in terms of demographic factors in the literature. It is considered that our study will fill the deficiency in this subject. For this purpose, firstly, information is given about the concepts of COCB, PC and $O C$, and past studies and researches examining these concepts in terms of demographic factors are included. Then, the results of the research on the subject are presented and after the similarities and differences with the literature and theories are revealed, practical suggestions that can be used especially by business managers are given for the evaluation of the findings.

\section{LITERATURE REVIEW}

The conceptual definition of $C O C B$, which is described as the dark side of $O C B$, which has been the subject of important studies in the literature, has been made in recent years and its dimensions have also been determined. Although the actions beyond the role definition are on a voluntary basis in OCB, these actions are not always done voluntarily and voluntarily (Bolino et al., 2004; 2010). In fact, the subject that applies to both the concepts of OCB-COCB is accepted as role behavior or job description. Because it is evaluated that role definitions in organizations cause negative perception of justice, create social and personal interpretation problems for employees and managers, and create employees who are forced to show extra role behavior despite their unwillingness. It is stated that the behaviors that are outside of the role definitions are included in the role definitions, and then they put pressure in the implementation of the role behaviors that are outside and require OCB (Vigado-Gadot, 2006). According to this way of thinking, OCB actually cause destructive and very harmful results, unlike many positive results listed in the literature. Vigado-Gadot (2007) named these acts of repression, not spontaneous, as "Compulsory Citizenship Behavior". According to this definition, contrary to the known $O C B$, the origin of the actions is not free will and the fact that they occur as a result of various compulsions reveals that $C O C B$ is a negative organizational behavior, unlike the $O C B$, which is a positive organizational behavior type (Peng \& Zhao, 2012; Zhao et al., 2013; Zhao \& Peng, 2014).

Psychology has introduced the concept of "Positive Psychology", which presupposes that the science of psychology can improve the positive aspects of the individual and work in particular, instead of dealing with only the negative aspects, and can be happy and productive (Gable and Haidt, 2005). The transition from positive psychology to the concept of positive organizational behavior and its definition was made by Luthans (2002). In this definition, in order to improve the working environment positively, there is the expression of studies aimed at increasing the psychological powers of the management on human resources in a measurable way (Luthans, 2002). Positive organizational behavior as a thought system are two new concepts that emerged as a result of the development of the concept of PC and positive psychology. The concepts of positive psychology and positive organizational behavior, which are in a cause and effect relationship, are considered to be the management of the organization with a strategic perspective by developing and managing the positive aspects of employees in today's competitive environment (Luthans and Youssef, 2004). Expressing who we are and where we can develop if we develop positively is defined as PC (Luthans, Youssef, \& Avolio, 2007). PC which has 4 dimensions in many sources; Optimism, hope, self-efficacy and psychological resilience are also described as components of PC.

The cynicism that is the basis of the concept of $\mathrm{OC}$ and described as a philosophy of life; It refers to moving away from both various pleasures and problems. In the first studies about cynicism among American employees, it is expressed as "not trusting the administrators and the rules" (Bateman et al. 1992). In many ways, attributing the foundations of the concept of OC constitute theories of expectation, social motivation, attitude, social exchange and emotional events (James, 2005). On the other hand, Andersson (1996) shows the lack of trust and hope for a person, a group, and a social environment; It defines it as a disappointing negative attitude. In another aspect, OC emerges with the effect of not meeting organizational expectations (Reichers et al. 1997). He defines OC as "negative attitude of the employee towards the company". Wilkerson et al. (2008) explains OC as "a negative attitude based on the idea that the procedures and processes of the organization the employee is in conflict with the interests of 
the employees". As a result, it is stated that OC can occur due to many reasons such as the perception of violation of social contract, organizational injustice, negative working conditions, negative leadership, and lack of communication (Cartwright and Holmes, 2006). In any case, it is considered that the reasons for OC are the reasons for the employee's loss of faith in his organization. Dean et al. (1998), three dimensions were developed and these are listed as cognitive, affective and behavioral dimensions.

Considering the studies in the literature regarding whether the COCB level differs in terms of demographic factors, there is no significant difference between the COCB levels of the employees in terms of marital status factor, according to the studies of Topçu and Beğenirbaş (2017). There is a significant difference between the COCB levels of employees in terms of age, which is another demographic factor. In terms of gender factor, the dominant number of men does not make possible any differential effect on the COCB level.

Considering the studies in the literature about whether the PC level differs in terms of demographic factors, Guan et al. (2017) and Rego vd. (2010) found a differentiation in terms of education factor in the form of an increase in PC levels as the education levels of employees increased. Werner and Smith (1982-1992), Cromer (2009), Finished (2014), Guan et al. (2017), it is determined that the age factor causes a significant difference mainly on PC. A significant part of these studies are consistent within themselves, as there are studies conducted among the service sector, academicians and healthcare professionals, in which career steps increase as the age increases. Gooty vd. (2009), Hsing-Ming et al., (2017) it was found that the gender factor has no effect on PC. Tepper (2000), Norman et al. (2010), Lehoczky (2013), and Guan et al. (2017), on the other hand, it is seen that gender creates a level difference only in the self-efficacy dimension.

Considering the studies conducted to determine whether the OC level differs in terms of demographic factors, Kanter and Mirvis (1989), Bateman (1992) and James (2005) found that demographic factors make a difference on OC and generally, as the education level increases, the OC level decreases. On the contrary, Dean vd. (1998), Abraham (2000), Brandes (2008), and Çalman (2016) found in their studies that education level did not cause any difference on OC. Although there are various results of studies on whether marital status, another demographic variable, creates a difference on OC, Kanter and Mirvis (1989) and Efilti (2008) found in their studies that the marital status did not have a significant effect on OC. Finally, in Efilti (2018) investigated whether it made a difference on $\mathrm{OC}$ and found that gender had no statistically significant effect on $O C$.

\section{DATA AND METHODOLOGY}

\subsection{Purpose and Model of the Research}

The purpose of this study is to examine whether the employees' COCB, PC and OC levels differ in terms of demographic factors. The target to be reached with this research; to examine the role of demographic factors in terms of high and low COCB, PC and OC levels of employees. The main hypotheses developed within the framework of the purpose of the research are as follows.

H1: The COCB level differs according to gender.

H2: The PC level differs according to gender.

H3: The OC level differs according to gender.

H4: The COCB level differs according to marital status.

H5: The PC level differs according to marital status.

H6: The OC level differs according to marital status.

H7: The COCB level differs according to education level.

H8: The PC level differs according to education level.

H9: The OC level differs according to education level.

H10: The COCB level differs according to age.

H11: The PC level differs according to age.

H12: The OC level differs according to age.

H13: The COCB level differs according to the institution's working time.

H14: The PC level differs according to the institution's working time.

H15:The OC level differs according to the institution's working time.

For the research application, a staple food producer operating in Gaziantep province and included in the ISO 500 list was selected. The reasons for choosing such a business for research are various, but primarily due to its proximity to the Middle Eastern countries in terms of geographic location. Therefore the export both possibilities and the ease of transportation in raw material 
imports thanks to the ports Iskenderun and Mersin. In addition, the relatively low number of researches conducted in the production sector is another reason for choosing such a business. 310 employees of the enterprise, which has a total of 1200 employees and operates in 5 main groups, were surveyed, and 305 of them were identified as valid, thus the data set was obtained.

\subsection{Data Collection Method}

The study was carried out with a questionnaire application, and demographic variables are present at the beginning of the 33question questionnaire form. In the study, a one-dimensional five-item scale with 0.96 validity and 0.88 reliability coefficients was used for COCB, which was created by Vigoda-Gadot (2007). In order to measure the OC, it was considered to use the 3-dimension scale composed of 13 items in total, which Brandes et al. (1999) created. This scale is actually a re-analyzed version of the first scale consisting of 14 items of the OC, which was created by Brandes in 1997. Kalağan (2009) tested the construct validity in his study, reached a positive result and found the reliability high. The 3-dimensional version of this scale has been verified with confirmatory factor analyzes and has taken its place in the Turkish literature as a valid and reliable scale (Kalağan, 2009: 128). Finally, to die PC, Luthans et al. (2007b), the result is reached with 4 dimensions and 24 items. These dimensions are hope, selfefficacy, psychological resilience and optimism, and a 24-item scale was created with 6 items for each. first performed the translation of this scale into Turkish and its validity and reliability analysis.

\subsection{Data Analysis Method}

The data set created by the survey method was analyzed using the SPSS-22 program. Initially, internal consistency values (Cronbach Alpha coefficients) were calculated to determine the reliability of the scales. In the next step, confirmatory factor analysis was performed to test the validity of the scales and the results are presented in another study. It is known that variables that are suitable for normal distribution give healthier results as a result of statistical analysis. Therefore, normality tests of COCB, PC and OC are performed before various analyzes to be made.

Table 1: Normality test results of COCB, PC and OC

\begin{tabular}{lccc}
\hline & COCB & PC & OC \\
\hline Mean & 2,783 & 3,9295 & 2,6159 \\
Median & 2,8345 & 4,1667 & $2,3269^{\mathrm{a}}$ \\
MOD & 3,4 & $4,33^{\mathrm{a}}$ & 4,54 \\
Varience & 1,242 & 0,699 & 1,316 \\
Skewness & 0,132 & $-1,491$ & 0,43 \\
Kurtosis & $-0,94$ & 1,599 & $-1,142$ \\
Smallest score & 1 & 1 & 1 \\
Highest score & 5 & 5 & 5 \\
\hline
\end{tabular}

Skewness and kurtosis values are used to test the normal distribution. Skewness refers to the symmetrical distribution of the observed values around the mean. Kurtosis also characterizes the distribution being sharp or extremely flattened. For this reason, kurtosis and skewness values outside certain limits endanger the health of the analysis.

While there are researchers who stated that kurtosis and skewness values should be between +1 and -1 (Hair et al., 2013), there are also researchers who say that these values should be between +1.5 and -1.5 . (Tabachnick and Fidel, 2013). George and Mallery (2010), on the other hand, evaluate that even kurtosis and skewness values between +2 and -2 are sufficient.

In the light of these considerations, it is seen that the skewness and kurtosis values of COCB, PC and OC in Table 1 are between $+1,5$ and $-1,5$ and only the kurtosis value of $P C$ is 1.59 .

Considering that the sample number of the research is 305 , it is thought that all our variables are suitable and conveinent for research. It has also been tested in the R.3.42 statistical program. Table 2 contains the results of the Shapiro Wilk normality test. 
Table 2: Shapiro Wilk Normality Test Results of COCB, PC and OC

\begin{tabular}{lc}
\hline Variable & p Value \\
\hline COCB & $p<0,001$ \\
PC & $p<0,001$ \\
$O C$ & $p<0,001$ \\
\hline
\end{tabular}

As a result of the examination, it was concluded that the variables were not normally distributed $(p<0.05)$. However, since the sample size of the study is 305 , it can be accepted that the variables are normally distributed according to the central limit theorem.

After it was understood that the data to be used in the study showed normal distribution, $t$ and ANOVA tests, which are among the parametric tests, were used to analyze this differentiation. For demographic variables consisting of two separate samples, gender and marital status are demonstrated by performing a t-test in relation to the mean of the two independent variables (Nakip, 2013). ANOVA (Analysis of Variance) test, which is the combination of the words that are the combination of $F$ test and Variance Analysis, was used to test the effects of other demographic factors on a variable of multiple factors (groups).

\section{FINDINGS AND DISCUSSIONS}

A significant portion of the employees of the food producing business are primary and high school graduates (Table 3). Undergraduate and graduate employees are white-collar administrators.

Table 3: Educational Status, Age, Institution Working Time, Branch Distribution of the Sample

\begin{tabular}{|c|c|c|c|c|c|c|c|}
\hline Education & $N(\%)$ & Age & $N(\%)$ & $\begin{array}{l}\text { Institution } \\
\text { Working Time }\end{array}$ & $N(\%)$ & $\begin{array}{l}\text { Branch } \\
\text { Distribution }\end{array}$ & $N(\%)$ \\
\hline Primary School & $142(\% 46)$ & $20-30$ & $87(\% 28,5)$ & 1,5 & $173(\% 56,7)$ & Forage & $67(\% 22,0)$ \\
\hline High School & $85(\% 27,9)$ & $31-40$ & $154(\% 50,5)$ & 6,10 & $101(\% 33,1)$ & Glucose & $60(\% 19,7)$ \\
\hline Associate Degree & $23(\% 7,5)$ & $41-50$ & $52(\% 17)$ & 11,15 & $22(\% 7,2)$ & Flour & $73(\% 23,9)$ \\
\hline Graduate & $53(\% 17,4)$ & $51-60$ & $11(\% 3,6)$ & 16,20 & $7(\% 2,3)$ & Pasta & $38(\% 12,5)$ \\
\hline $\begin{array}{l}\text { Post } \\
\text { Graduate }\end{array}$ & $2(\% 0,7)$ & $61-70$ & $1(\% 0,3)$ & 21,25 & $2(\% 0,7)$ & Starch & $67(\% 22,0)$ \\
\hline
\end{tabular}

Again, when we examine Table 3, we see that employees between the ages of 31-40 make up half of the total number. Combined with $28,5 \%$ between the ages of $20-30$, it would not be wrong to say that $79 \%$ of them are blue-collar workers. In the enterprise, those with a working period of 1-5 years have a significant weight, such as $56 \%$. Those who have a working period of less than 10 years are $89,8 \%$. At this point, it would not be wrong to say that the vast majority of employees have a working period of less than 10 years. One of the reasons for this is thought to be the new opening of starch feed and glucose units (Table 3). It is seen in Table 3 that the ratio of the number of employees of the five main fields of activity of the enterprise in the sample is approximately equal. In addition, the fact that the pasta production facilities have largely switched to automation systems explains the relatively low number of employees.

According to Table 4, we can see the weight of man employees with a rate of $89,2 \%$ regarding gender distribution. This can be considered as a relatively high rate, especially for a food production establishment where body strength is important. In addition, if we leave aside the employees between the ages of $20-30$, which is $28,5 \%$, it is seen that there are $80 \%$ of married employees.

Table 4: Gender Distribution and Marital Status Distribution of the Sample

\begin{tabular}{llll}
\hline Gender & $\mathbf{N}(\%)$ & Marital status & $\mathbf{N}(\%)$ \\
\hline Woman & $33(\% 10,8)$ & Married & $244(\% 80,0)$ \\
Man & $272(\% 89,2)$ & Single & $61(\% 20,0)$ \\
\hline
\end{tabular}

T-test was conducted for gender and marital status demographic factors. The number of samples (N), standard deviation, mean, $t$ and $p$ values are important in revealing the findings of the $t$ test. Apart from these Levene Variances Equality Test 2-part Sig. It can be meaningful or meaningless depending on its value (Nakip, 2013). The t-test results of COCB, PC and OC according to gender, which are one of the dual demographic variables, are shown in Table 5. 
Table 5: T Test Results for Determining the Difference according to Gender

\begin{tabular}{ccccccc}
\hline & Gender & N & Mean & $\begin{array}{c}\text { Standard } \\
\text { Deviation }\end{array}$ & t & $\mathbf{p}$ \\
\hline \multirow{2}{*}{ COCB } & Man & 272 & 2,80 & 1,11 & $-1,131$ & 0,259 \\
& Woman & 33 & 2,57 & 1,09 & $-1,152$ & 0,256 \\
\hline \multirow{2}{*}{ PC } & Man & 272 & 3,95 & 0,80 & $-1,707$ & 0,089 \\
& Woman & 33 & 3,95 & 1,01 & $-1,432$ & 0,161 \\
\hline \multirow{2}{*}{ OC } & Man & 272 & 2,61 & 1,13 & $-0,077$ & 0,939 \\
& Woman & 33 & 2,60 & 1,26 & $-0,070$ & 0,944 \\
\hline
\end{tabular}

It was found that the $C O C B$ level of the sample did not show a significant difference according to gender $(t=-1,131 ; p=0,259>0,05)$ while the COCB level of employees is 2.80 ( $S D=1.11$ ) for man and 2.57 (SD = 1.09) for womans. Although the COCB level is slightly higher in man, the difference is not significant. According to this result, our hypothesis that "H1: The COCB level differs according to gender" was rejected. Similarly, no significant difference was found in the PC levels of the employees in terms of gender factor ( $\mathrm{t}=-1.707 ; \mathrm{p}=0.161>0.05)$. The mean PC levels of man and woman are the same $(3,95)$. So our hypothesis that "H2: The $P C$ level differs according to gender" was rejected. Lastly, no significant difference was found among the employees in terms of gender factor at the OC level $(t=-0.077$ and $p=0.939>0.05)$. Man and woman average OC levels are almost the same. According to this result, our hypothesis that "H3: The OC level differs according to gender" was rejected.

Table 6 shows the values of COCB, PC and OC according to the marital status two-dimensional sample factor. It is seen that this status of married and single workers has a significant relationship with the COCB level $(t=2.337 ; p=0.017<0.05)$. In this respect, our hypothesis that "H4: The COCB level differs according to marital status" was accepted. It was found that the COCB level of the married workers was 2.85 (SD =1.09), while the COCB level of the single workers was behind with the value of 2.47 (SD =1.14). It is considered that the reason for this is that married employees, who have a family they have to care for, feel under pressure to perform OCB and not lose their jobs.

However, it was observed that the marital status of the employees did not have a significant relationship with PC levels ( $t=-1.179$; $p=0.239>0.05)$. Therefore, the hypothesis that "H5: The PC level differs according to marital status" was rejected.

In OC, which is a negative organizational behavior concept, the situation is similar to COCB. There is a significant difference between single and married staff in terms of level with the values of $O C t=3,268$ and $p=0,02<0,05$. In this respect, our hypothesis that "H6: The OC level differs according to marital status" was accepted. Similar to the COCB level, higher levels of married employees compared to singles at OC levels are considered to be a family entity that needs to be supported.

Table 6: T Test Results for Determining the Difference according to Marital Status

\begin{tabular}{ccccccc}
\hline & Marital Status & N & Mean & Standard Deviation & t & p \\
\hline \multirow{2}{*}{ COCB } & Married & 244 & 2,85 & 1,09 & 2,402 & 0,017 \\
& Single & 61 & 2,47 & 1,14 & 2,337 & 0,022 \\
\hline \multirow{2}{*}{ PC } & Married & 244 & 3,90 & 0,86 & 1,179 & 0,239 \\
& Single & 61 & 4,04 & 0,71 & 1,319 & 0,190 \\
\hline \multirow{2}{*}{ OC } & Married & 244 & 2,71 & 1,14 & 3,119 & 0,002 \\
& Single & 61 & 2,21 & 1,06 & 3,268 & 0,001 \\
\hline
\end{tabular}

Whether there is a difference in the level of $p<0.05$ significance of $C O C B, P C, O C$ according to education levels is evaluated according to Table 7.

Table 7: Anova Test Results to Determine the Difference according to Education Level

\begin{tabular}{|c|c|c|c|c|c|c|}
\hline & \multirow{2}{*}{ Education Level } & \multirow{2}{*}{$\mathbf{N}$} & \multirow{2}{*}{ Mean } & \multirow{2}{*}{$\begin{array}{l}\text { Standard } \\
\text { Deviation }\end{array}$} & \multicolumn{2}{|c|}{ Anova Test } \\
\hline & & & & & $\mathbf{F}$ & $\mathbf{P}$ \\
\hline \multirow{3}{*}{ COCB } & Primary School & 142 & 3,0634 & 1,09658 & & \\
\hline & High School & 85 & 2,6494 & 1,20036 & 5,094 & 0,001 \\
\hline & Associate Degree & 23 & 2,5043 & 87359 & & \\
\hline
\end{tabular}




\begin{tabular}{|c|c|c|c|c|c|c|}
\hline & Graduate & 53 & 2,4038 & \multicolumn{3}{|l|}{,93602 } \\
\hline & Post Graduate & 2 & 1,8 & \multicolumn{3}{|l|}{,84853 } \\
\hline & Total & 305 & 2,783 & \multicolumn{3}{|l|}{1,11460} \\
\hline \multirow{6}{*}{ PC } & Primary School & 142 & 3,7412 & ,95762 & \multirow{6}{*}{3,956} & \multirow{6}{*}{0,004} \\
\hline & High School & 85 & 4,173 & ,53639 & & \\
\hline & Associate Degree & 23 & 4,0254 & ,77267 & & \\
\hline & Graduate & 53 & 3,9914 & ,82039 & & \\
\hline & Post Graduate & 2 & 4,2083 & ,47140 & & \\
\hline & Total & 305 & 3,9295 & ,83601 & & \\
\hline \multirow{6}{*}{ OC } & Primary School & 142 & 2,9085 & 1,15978 & \multirow{6}{*}{5,013} & \multirow{6}{*}{0,001} \\
\hline & High School & 85 & 2,4362 & 1,10120 & & \\
\hline & Associate Degree & 23 & 2,1706 & 1,01042 & & \\
\hline & Graduate & 53 & 2,3498 & 1,08162 & & \\
\hline & Post Graduate & 2 & 1,6538 & 38075 & & \\
\hline & Total & 305 & 2,6159 & 1,14711 & & \\
\hline
\end{tabular}

As can be seen from Table 7, it has been found that the level of COCB makes a significant difference according to the education level $(F=5.094 ; p=0.001<0.05)$. In this case, our hypothesis that "H7: The COCB level differs according to education level" was accepted. According to the education level, the highest COCB level was found among primary school graduates with 3.06 (SD $=$ 1.09). Following this, it has been determined rhat they have $2.64(S D=1.20)$; high school graduates with 2.50 (SD $=0.84)$, associate degree, $2.40(S D=0.94)$, undergraduate and $1.8(S D=0.84)$, respectively, and the level of COCB decreases with increasing education level. This situation is caused by the rise from blue-collar to white-collar and from employee to manager as the level of education increases; It is considered to be understandable that blue-collar workers with a low education level are under pressure to show higher COCB.

It was observed that the PC level significantly differed according to the education levels $(F=3.956 ; p=0.004<0.05)$. Therefore, our hypothesis that "H8: The PC level differs according to education level" was accepted. The highest PC level was found to be 4.20 (SD = 0.47) among graduates and the lowest PC levels was $3.74(S D=0.95)$ among primary school graduates. PC levels of undergraduate, associate degree and high school graduates do not show a linear change, but there is no significant difference between them. In this respect, it is found that PC levels increase with the education level. The reason for this is thought to be that as the level of education increases, the hierarchical level increases, and authority and responsibility increase.

It was understood that $\mathrm{OC}$ levels among employees also differ with their education level $(F=5.013 ; p<0.05)$. According to these results, the hypothesis that "H9: The OC level differs according to education level" was accepted. It would not be wrong to conclude that education level suppresses negative organizational behavior in $\mathrm{OC}$, which is a negative organizational behavior type like COCB. In fact, as the level of education increases, the rise in the hierarchical level is known as a phenomenon that is generally experienced in enterprises. In addition, as the hierarchical level rises, increasing responsibilities and power of management, in other words, authority begins to constitute the source of behaviors that cause cynical attitude. In other words, the manager is not expected to be both cynical and exhibit a management style that causes cynical attitude.

It was determined from Table 8 that the age range factor of our sample did not differ with the level of $\operatorname{COCB}(F=0.377 ; p=0.825>$ 0.05). For this reason, the hypothesis that "H1O: The COCB level differs according to age" was rejected. At this point, we are faced with the fact that an increase in the age range does not mean an increase in hierarchical levels as it is in the education level.

Table 8: F Test Results regarding the Age Variable

\begin{tabular}{ccccccc}
\hline & Age & N & Mean & Standard & \multicolumn{2}{c}{ Anova Test } \\
\cline { 5 - 7 } & $20-30$ & 87 & 2,7057 & 1,08856 & & $\mathbf{P}$ \\
\hline \multirow{3}{*}{ COCB } & $31-40$ & 154 & 2,7870 & 1,13775 & & \\
& $41-50$ & 52 & 2,8962 & 1,16383 & 0,377 & 0,825 \\
& $51-60$ & 11 & 2,8727 &, 82109 & & \\
& $61-70$ & 1 & 2,0000 & & & \\
& & & & & & \\
\end{tabular}




\begin{tabular}{|c|c|c|c|c|c|c|}
\hline & Total & 305 & 2,7830 & 1,11460 & & \\
\hline \multirow{6}{*}{ PC } & $20-30$ & 87 & 4,0120 & 0,75598 & \multirow{6}{*}{0,663} & \multirow{6}{*}{0,618} \\
\hline & $31-40$ & 154 & 3,8696 & 0,87825 & & \\
\hline & $41-50$ & 52 & 3,9135 & 0,91510 & & \\
\hline & $51-60$ & 11 & 4,1780 & 0,27201 & & \\
\hline & $61-70$ & 1 & 4,0833 & & & \\
\hline & Total & 305 & 3,9295 & 0,83601 & & \\
\hline \multirow{5}{*}{ OC } & $20-30$ & 87 & 2,4757 & 1,12152 & \multirow{5}{*}{0,961} & \multirow{5}{*}{0,429} \\
\hline & $31-40$ & 154 & 2,6508 & 1,16849 & & \\
\hline & $41-50$ & 52 & 2,8062 & 1,16326 & & \\
\hline & $51-60$ & 11 & 2,4196 & 0,94234 & & \\
\hline & Total & 305 & 2,6159 & 1,14711 & & \\
\hline
\end{tabular}

Similarly, the age range is not significantly effective at the PC level $(F=0.663 ; p=0.618>0.05)$ due to its values. So the "H11: The $P C$ level differs according to age" hypothesis is rejected. It was found that the age demographic variable $(F=0.96 ; p=0.42>0.05)$ values did not have a significant effect on OC. For this reason, the hypothesis "H12: The OC level differs according to age" was rejected.

In Table 9, it is determined that there is no significant difference in terms of institution's working time on $\operatorname{COCB}(F=1.16 ; p=0.32>$ 0.05). For this reason, the hypothesis that "H13: The COCB level differs according to the institution's woking time" was rejected. There is no significant difference on $\mathrm{PC}(\mathrm{F}=1.09 ; \mathrm{p}=0.36>0.05$ in terms of institution's working time. At this point, the hypothesis that "H14: The PC level differs according to theinstitution's working time" was rejected. Institution working time was found to be $(F=0.67 ; p=0.61>0.05)$ for OC. This situation shows that there is no significant difference in terms of institution's working time on the OC. So, the hypothesis that "H15: The OC level differs according to the institution's working time" was also not accepted.

Table 9: F Test Results Related to the Variables of the Institution's Working Time

\begin{tabular}{|c|c|c|c|c|c|c|}
\hline & \multirow{2}{*}{$\begin{array}{c}\text { Institution's Working } \\
\text { Time }\end{array}$} & \multirow[b]{2}{*}{$\mathbf{N}$} & \multirow[b]{2}{*}{ Mean } & \multirow{2}{*}{$\begin{array}{l}\text { Standard } \\
\text { Deviation }\end{array}$} & \multicolumn{2}{|c|}{ Anova Test } \\
\hline & & & & & $\mathbf{F}$ & $\mathbf{P}$ \\
\hline \multirow{6}{*}{ COCB } & $1-5$ & 173 & 2,7156 & 1,15941 & \multirow{6}{*}{1,162} & \multirow{6}{*}{0,328} \\
\hline & $6-10$ & 101 & 2,9129 & 1,03939 & & \\
\hline & $11-15$ & 22 & 2,5364 & 1,08036 & & \\
\hline & $16-20$ & 7 & 3,1429 & 1,12969 & & \\
\hline & $21-25$ & 2 & 3,5000 & 0,70711 & & \\
\hline & Total & 305 & 2,7830 & 1,11460 & & \\
\hline \multirow{6}{*}{ PC } & $1-5$ & 173 & 3,9217 & 0,82793 & \multirow{6}{*}{1,092} & \multirow{6}{*}{0,361} \\
\hline & $6-10$ & 101 & 3,8775 & 0,88884 & & \\
\hline & $11-15$ & 22 & 4,0152 & 0,75237 & & \\
\hline & $16-20$ & 7 & 4,5179 & 0,30605 & & \\
\hline & $21-25$ & 2 & 4,2292 & 0,26517 & & \\
\hline & Total & 305 & 3,9295 & 0,83601 & & \\
\hline \multirow{6}{*}{ OC } & $1-5$ & 173 & 2,5598 & 1,15514 & \multirow{6}{*}{0,675} & \multirow{6}{*}{0,61} \\
\hline & $6-10$ & 101 & 2,7449 & 1,15359 & & \\
\hline & $11-15$ & 22 & 2,4126 & 1,16407 & & \\
\hline & $16-20$ & 7 & 2,6484 & 0,81512 & & \\
\hline & $21-25$ & 2 & 3,0769 & 1,19664 & & \\
\hline & Total & 305 & 2,6159 & 1,14711 & & \\
\hline
\end{tabular}

As a result, the summary of the analysis results regarding whether the levels of $C O C B, P C$ and OC differ according to demographic factors are shown collectively in Table 10. 


\begin{tabular}{lc}
\hline DEMOGRAPHIC FACTORS OF THE EMPLOYEES & Acceptance/Rejection \\
\hline H1: The COCB Level Differs According to Gender & Rejection \\
H2: The PC Level Differs According to Gender & Rejection \\
H3: The OC Level Differs According to Gender & Rejection \\
H4: The COCB Level Differs According to Marital Status & Acceptance \\
H5: The PC Level Differs According to Marital Status & Rejection \\
H6: The OC Level Differs According to Marital Status & Acceptance \\
H7: The COCB Level Differs According to Education Level & Acceptance \\
H8: The PC Level Differs According to Education Level & Acceptance \\
H9: The OC Level Differs According to Education Level & Acceptance \\
H10: The COCB Level Differs According to Age & Rejection \\
H11: The PC Level Differs According to Age & Rejection \\
H12: The OC Level Differs According to Age & Rejection \\
H13: The COCB Level Differ According to the Institution's Working Time & Rejection \\
H14: The PC Level Differs According to the Institution's Working Time & Rejection \\
H15: The OC Level Differs According to the Institution's Working Time & Rejection \\
\hline
\end{tabular}

Accordingly, gender and marital status factors were analyzed with the t-test, education status, age and institutional working time with the $\mathrm{F}$ test. Of these, a statistically significant correlation was found between the educational status of $C O C B, P C$ and $O C$, while a significant relationship was observed between the marital status factor on COCB and OC, while no statistically significant relationship was found on PC. In addition, there are no statistically significant relationships between gender, age, and institutional working time on $\mathrm{COCB}, \mathrm{PC}$ and $\mathrm{OC}$. The marital status factor does not show a statistically significant relationship with $\mathrm{PC}$, which is a positive organizational behavior variable. On the contrary, in the negative organizational behavior variable $C O C B$ and $O C$, a higher level is observed in married couples compared to singles. Its relevance to literature and theories is made in the discussion section.

\section{CONCLUSION}

While there is no significant effect of institution working duration, age and gender factors on COCB level, there is a significant effect of marital status and educational status factors. It has been found that there is a significant difference between the levels of COCB according to marital status. This result we have obtained is not compatible with the literature. However, it is evaluated that married employees may feel under pressure due to the fear of job loss in the cyclically increasing unemployment environment. It has been determined that there is a significant difference between the COCB levels of the employees according to their education level. This result is in accordance with the literature. This situation is caused by the rise from blue collar to white collar and from employee to manager as the level of education increases; It is considered that it is understandable that blue-collar workers with low education levels are under pressure to show higher COCB. In the study performed, it was determined by the $\mathrm{F}$ test that the level of $\mathrm{COCB}$ was not affected by the age demographic factor. This result is compatible with the literature. In the examination, it is seen that the age groups are homogeneously distributed on the factors that we previously determined to have an effect on the level of $C O C B$, such as the level of education. This explains the fact that the age factor does not have a difference in the effect of the COCB level. There was no difference in the level of COCB according to the duration of the institution. When the agency working time frequencies are controlled, it is seen that a very high group has a high labor turnover rate. Therefore, this group determines the COCB level. According to the gender factor, no significant difference was found in the COCB levels of employees. The dominant number of males, with a significant proportion, does not make any differential effect on the level of COCB. This result is compatible with the literature (Topçu and Beğenirbaş, 2017).

In our study, only the education level was effective on the PC level among the demographic factors; It was found that there was no effect of age, institution working time, gender and marital status. It is seen that these results are substantially confirmed when compared with various studies in the literature. According to our analysis results, the level of education has a significant effect on the PC level of the employees. Accordingly, as the education level increases, an increase is observed in the PC level. This result is highly consistent with various studies in the literature. Studies that detect differences in PC levels according to education levels find that PC levels increase as the education level increases (Guan et al., 2017). In our study, the first demographic variable that has no effect on PC level among employees is age. There are studies with findings in this direction in the literature. However, 
there is predominantly a relationship between age and PS level (Guan et al., 2017: 6; Werner and Smith, 1982: 1992). A significant part of these studies are consistent within themselves, as there are studies conducted among the service sector, academicians, and healthcare professionals in which career steps increase as the age increases.

Our findings, which determined that there is no effect of the working time of the institution on the PC level, are in parallel with some of the other studies in the literature (Luthans et al., 2007a; Luthans et al., 2008). In some studies, the duration of working in the institution is effective in some of the PC and its sub-dimensions (Guan et al., 2017; Hsing-Ming et al., 2017). Considering these results, the fact that there is no result of the working time of the institution for the PC level, which is our analysis result, is in parallel with some of the literature. The fact that our sample is in the production sector and the numerical excess of blue-collar workers prevents the increase as the working time in the institution increases. This result is actually similar to the age factor and is consistent within itself. It is among the findings of our study that gender, another demographic factor, has no effect on PC level. This result shows parallelism with most of the studies in the literature. In some studies, it is seen that gender only creates a level difference in the dimension of self-efficacy (Guan et al., 2017; Lehoczky, 2013; Norman et al.,2010). The majority of our sample, which is in the manufacturing sector, consists of male employees, and numerical superiority is considered to be determinant. Another demographic factor whose effect on PC-related level could not be determined is marital status. At this point, when the relevant literature is examined, similarly, a relationship between PC level and marital status factor cannot be found in some studies. However, in some studies, it is evaluated that marital status affects the level of PC and the institution of marriage is effective in getting away from stress (Guan et al., 2017). In our study, it is considered that this factor has lost its distinctiveness because the rate of married people is very high and there are predominantly married employees.

When we look at the effect of demographic factors on OC, which we examined as a dependent variable, our first and important finding is that we have access to the findings in OC as a whole. While OC is detected at different levels according to educational status and marital status, it is determined by our analysis results that age, working time in the institution and gender do not have any effect on $O C$ level. The OC level differs according to the education level. Similar to COCB, the higher the education level, the lower the OC level. It is seen that this result is compatible with other studies in the literature (Bateman, 1992; James, 2005; Kanter and Mirvis, 1989). In our study, it is thought that the positive effects of education level suppress the level of OC, which is a negative organizational behavior variable. According to our research findings, OC level is affected statistically significantly according to marital status factor. In addition, it is observed that the OC level is higher in married workers. In addition, it should be taken into account that a large proportion of our sample is married. In the examination and comparison made in the literature, it is seen that there are various results regarding the effect of marital status on OC. Some of the researchers find that marital status affects OC. However, it should be noted that these studies have determined that single people have higher OC levels (Kanter and Mirvis, 1989). As a result, there is a significant difference between the findings of our study and the literature. It is considered that the most important factor in this is that our work is done in the production sector, although most of the studies in the literature have been done in sectors such as service, tourism, health, education and security.

Our finding that the age groups of the employees do not have a statistically significant effect on OC is in great agreement with the literature. In addition, there are studies that found that $\mathrm{OC}$ and its sub-dimensions vary according to the demographic factor of age. In our study, it is considered that it would be more accurate to explain the ineffectiveness of the age factor on OC with the internal dynamics of the business. It is thought that the presence of employees from every group in every department, duty and branch, as in many of the production enterprises, prevents clustering at the OC level. Our finding that the duration of working in the institution does not have any effect on $\mathrm{OC}$ is compatible with a significant part of the studies in the literature. In addition, there are also studies that have found statistically significant relationships between the working hours of the institution and OC. A very significant part of the employees have a working time of 10 years or less. It is therefore self-consistent that the working year is not a distinguishing factor. It is considered that this issue arises from the high labor turnover rate in the production sector. According to our analysis results, it is evaluated that gender does not have any effect on OC levels, similar to COCB and PC. When the compatibility of this with the literature is checked, it is seen that similar findings are obtained in many studies (Efilti, 2008). However, there are also studies that found that gender has a statistically significant effect on OC reduces discrimination (Lobnikar \& Pagon, 2004; Mirvis \& Kanter, 1991). The relative density of male workers in the production sector is considered as an antecedent of this.

It is a known fact that negative organizational behavior concepts from a management point of view cause more harm than positive organizational behavior concepts contribute to organizations. Therefore, the focus should be on increasing the PC level in order to reduce the COCB and OC levels. As a solution for higher PS level and lower COCB and OC level, it can be recommended to prefer more educated and single personnel in terms of marital status factor. Considering the educational demographic factor, which has statistically significant relationships with the variables, it is generally concluded that the higher the education level, the higher the 
PC level, the lower the COCB and OC levels. In other words, high level of education positively affects the variables of organizational behavior; It also decreases the level of negative organizational behavior variables. At this point, rather than dealing with COCB, PC and OC separately, it is considered that taking the necessary approaches to all of them at the same time will have a synergetic effect. In the light of all these results, it is clear that business managers should ensure development and innovation by using many disciplines together.

As a result of the results of this study, future research anda few suggestions can be made for applications. In this context, the study can be carried out by enriching it with different demographic variables, or it can be handled in more detail, including the sample in which different participants are handled, occupational groups and regional differences. In addition, demographic variables in this study its direct effects on COCB, PC and OC have been demonstrated. It can be suggested that researchers working in this field should analyze the direct and indirect relationships between the variables and work on a holistic model that will determine the mediating or regulatory roles of the variables.

\section{REFERENCES}

Abraham, R. (2000). Organizational cynicism; bases and consequences. Genitc, Social and General Psychology Monographs, $126(3), 269-292$.

Andersson, L. (1996). Employee cynicism: An examination using a contract violation framework. Human Relations, $49,1395-1418$.

Bateman, T.S., Sakano, T., Fujita, M. (1992). Roger, me and my attitude film propaganda and cynicism toward corporate leadership. The Journal of Applied Psychology, 77(5), 768-771.

Bolino, M.C., Turnley, W.H. , Niehoff, B.P. (2004). The other side of the story reexamining prevailing assumptions about organizational citizenship behavior. Human Resource Management Review, 14(2), 229-246.

Brandes, P.M. (1997). Organizational cynicism its nature antecedents and consequences. Unpublished Doctoral Dissertation, University of Cincinnati, Ohio.

Brandes, P., Dharwadkar, R., Dean, W.J., (1999).Does organizational cynicism matter? Employee and supervisor perspectives on work outcomes eastern academy of management proceedings. New York: JAI Press.

Cartwright, S. ve Holmes, N. (2006). The ortalamaing of work the challenge of regaining employee engagement and reducing cynicism. Human Resource Management Review, 16, 199-208.

Cromer, K.W. (2009). A conceptual model of volunteer engagement the influence of organizational assimilation and psychological capital constructs as reflections of overall volunteer engagement attitude on multidimensional and overall individual effective volunteer behavior. Unpublished Doctoral Dissertation, TUI University, College of Business Administration, Los Angeles.

Dean, J.W., Brandes, P., Dharwadkar, R. (1996). Organizational cynicism. The Academy of Management Review, 23(2), 341-352.

Efilti, S., Gönen, Y., Öztürk, F. (2008). Organizational cynicism a field study on executive secretaries working at Akdeniz University. 7th National Office Management and Secretariat Congress, Karadeniz Technical University, Trabzon, 1-14.

Gable, S.L., Haidt, J. (2005). What (and why) is positive psychology? Review of General Psychology, 9(2), $103-110$.

George, D., Mallery, M. (2010). SPSS for windows step by step a simple guide and reference. Boston: Pearson Inc.

Guan, C.S., Li, Y., Ma, H. (2017). The mediating role of psychological capital on the association between occupational stress and job satisfaction among township cadres in a specific province of china a cross sectional study. International Journal of Environmental Research and Public Health, 14(9), 1-12.

Hair, J. F., Black, W. C., Babin, B. J., Anderson, R. E., Tatham, R. L. (2013). Multivariate Data Analiz Pearson Education Limited.

Hsing-Ming, L., Mei-Ju, C., Chia-Hui, C., Ho-Tang, W. (2017). The relationship between psychological capital and professional commitment of preschool teachers the moderating role of working Years. Universal Journal of Educational Research, 5(5), 891-900.

James, M.L. (2005). Antecedents and consequences of cynicism in organizations an examinatıon of the potential positive and negative effects on school systems. Unpublished Doctoral Dissertation, The Florida State University, Florida.

Kalağan, G., (2009). The relationship between research assistants' perceptions of organizational support and their organizational cynicism. Unpublished Master's Thesis, Akdeniz University Institute of Social Sciences, Antalya.

Kanter, D.L., Mirvis, P.H. (1989). The cynical americans: Living and working in an age of discontent and disillusion. San Francisco: Jossey-Bass.

Lehoczky, M.H. (2013). The socio-demographic correlations of psychological capital. European Scientific Journal, 9(2), $26-42$. 
Lobnikar, B., Pagon, M.(2004). The prevalence and nature of police cynicism in Slovenia from policing in Central and Eastern Europe dilemmas of contemporary criminal justice.Gorazd Mesko, Milan Pagon.

Luthans, F. (2002). Positive organizational behavior developing and managing psychological strengths. Academy of Management Executive, 16, 57-72.

Luthans, F., Youssef, C.M. (2004). Human social and now positive psychological capital management investing in people for competitive advantage. Organizational Dynamics, 32, 141-152.

Luthans, F., Avolio, J.B., Avey, S.M. (2007a). Positive psychological capital measurement and relationship with performance and satisfaction. Personel Psychology, 60, 541-572.

Luthans, F., Youssef, C.M., Avolio B.J. (2007b). Psychological capital. New York: Oxford University Press.

Luthans, F., Norman, S.M., Avolio, B.J., Avey, J.B. (2008). The mediating role of performance relationship. Journal of Organizational Behavior, 28, 219-238.

Mirvis, P.H., Kanter, D.L. (1991). Beyond demography a psychograpic profile of the workforce. Human Resource Management, 30(1), 51-52.

Norman, S.M., Avey, J., Nimnicht, J.L., Pigeon, N. (2010). The interactive effects of psychological capital and organizational identity on employee organizational citizenship and deviance behaviors. Journal of Leadership and Organizational Studies, 17(4), 380-391.

Peng, Z.L., Zhao, H. (2012). Does organization citizenship behavior really benefit the organization? Study on the compulsory, citizenship behavior in China. Nankai Business Review International, 8(3), 75-92.

Rego, A., Marquez, C., Leal, S., Sousa, F., Cunha, M.P. (2010). Psychological capital and performance of portuguese civil servants exploring neutralizers in the context of an appraisal system the international. Journal of Human Resource Management, 21(9), $1531-1552$.

Reichers, A.E., Wanous, J.P., Austin, J.T. (1997). Understanding and managing cynicism about organizational change. Academy of Management Executive, 11(1), 48-59.

Tabachnick, L., Fidell T., (2013). Using multivariate statics. Boston: Pearson Book.

Topçu, M.K., Beğenirbaş, M. (2017). Organizational cynicism is an application in the manufacturing industry to determine the effects of compulsory organizational citizenship behaviors and job satisfaction on individual job performance. Unpublished Doctorate Thesis, Celal Bayar University Faculty of Economics and Administrative, Manisa.

Vigoda-Gadot, E. (2007). Redrawing the boundaries of OCB? An empirical examination of compulsory extra role behavior in the workplace. Journal of Business and Psychology, 21, 377-405.

Werner, E.E., Smith, R.S. (1982-1992). A study of resilient children. New York: McGraw-Hill.

Wilkerson, J.M., Evans. W.R., Davis, W.D. (2008). A test of coworkers influence on organizational cycisicm badmounthing and organizational citizenship behavior. Journal of Applied Social Pyscology, 8(3), 2273-2292.

Zhao, H., Peng, Z., Han, Y., Sheard, G. ve Hudson, A. (2013). Psychological mechanism linking abusive supervision and compulsory citizenship behavior a moderated mediation study. The Journal of Psychology, 147(2), 177-195.

Zhao, H., Peng, Z., Chen, H.K. (2014). Compulsory citizenship behavior and organizational citizenship behavior the role of organizational identification and perceived interactional justice. The Journal of Psychology, 148(2), 177-196. 